Article

\title{
Creating Community and Belonging in a Designated Housing Estate for Disabled People
}

\author{
Liz Ellis *, Sarah-Anne Muñoz, Katia Narzisi, Sara Bradley and Jenny Hall \\ Division of Rural Health and Wellbeing, University of the Highlands and Islands, Inverness, IV2 3JH, Scotland; \\ E-Mail: liz.ellis@uhi.ac.uk (L.E.), sarah-anne.munoz@uhi.ac.uk (S-A.M.), katia.narzisi@uhi.ac.uk (K.N.), \\ sara.bradley@uhi.ac.uk (S.B.), jenny.hall@uhi.ac.uk (J.H.) \\ * Corresponding author
}

Submitted: 15 January 2020 | Accepted: 21 April 2020 | Published: 31 July 2020

\begin{abstract}
In recent years there has been an ideological push within social care away from segregated housing provision towards supported housing integrated within the wider community (McConkey, Keogh, Bunting, Iriarte, \& Watson, 2016; Merrells, Buchanan, \& Waters, 2019; Overmars-Marx, Thomése, Verdonschot, \& Meininger, 2014). Despite this, many housing solutions for older and disabled people continue to be built on a designated basis, with physical and emotional wellbeing outcomes being both contested and mixed. After reviewing key policy relating to social care housing alongside some of the theoretical and ideological positions, this article explores the social and emotional outcomes of a diverse group of disabled people living with mental health difficulties, physical and intellectual impairments, illnesses and age-related conditions, who moved into a small, purpose-built estate of smart homes. Drawing primarily on qualitative data collected from tenants prior to moving and again seven months following relocation, the impact of moving into the estate on tenants' sense of wellbeing and feelings of inclusion will be analysed and discussed in relation to efforts to build a new community.
\end{abstract}

\section{Keywords}

community building; disabled people; housing; loneliness; smart homes; wellbeing

\section{Issue}

This article is part of the issue "Home, Housing and Communities: Foundations for Inclusive Society" edited by Isobel Anderson (University of Stirling, UK), Vikki McCall (University of Stirling, UK) and Joe Finnerty (University College Cork, Ireland).

(C) 2020 by the authors; licensee Cogitatio (Lisbon, Portugal). This article is licensed under a Creative Commons Attribution 4.0 International License (CC BY).

\section{Introduction}

Housing arrangements for older and disabled people have been the site of contention for a long period. There has been conflict between policy makers and older and disabled people over affordability and personal choice, as well as arguments within academia over the (de)merits of clustered, specialist and mainstream housing within the wider community (cf. Bigby, 2004; Cummins \& Lau, 2004; Emerson, 2004a, 2004b).

Whilst much of the recent discussion has been around provision for people with learning difficulties, similar issues apply to older and disabled people and indeed, the UK government conflates older and disabled people within policy (Ministry of Housing Communities \& Local Government, 2019). In addition, an ageing population of disabled and non-disabled people has driven demand for independent living within mainstream communities. However, the impact of austerity on state provision of social housing and concurrent neoliberal imperatives to monetise social care provision over the past decade (Power \& Gaete-Reyes, 2019) has resulted in the increasing use of specialist accommodation tied to provision of support by multinational organisations and large charities.

This article explores the establishment of a community of disabled people who moved into a designated housing estate of SmartBodes in Scotland. We outline 
the UK policy and practice for housing solutions aimed at disabled people and some of the tensions that arise, particularly with regard to housing that is tied to support, in order to contextualise how the SmartBodes represent a different approach before introducing the site of the SmartBodes and its residents. We go on to analyse the key themes of loneliness, community building and support, finding that this new, hybrid form of social housing helped to promote feelings of social connection and community for many of the residents.

\section{The Policy Context}

Scotland, the location of this intervention, has a different policy context to the rest of the UK. Since 2002, personal care has been free for those over 65 , provided they have been assessed as requiring it by social services. In April 2019, the Scottish Government brought in Frank's Law, entitling all adults over 16 to claim free personal care. Someone assessed as requiring personal care receives this whatever their income or marital status. Conversely, in England and Wales, most people pay some or all of their personal care costs (NHS, 2018).

Depending on financial assessment, people can still be charged for the following services which are not deemed to be personal care: telecare (e.g., community alarms), lunch clubs, care home accommodation/food, housework, laundry, shopping services, day services and transport. People living at home can choose how they receive these services, which are listed in individual care plans. Care at home services can be offered by the local authority or by an external organisation under contract to the local authority. In Scotland disabled people access Self-Directed Support which aims to give people more control over their care delivery. The following options are offered:

1. Direct payments enabling people to buy care and support themselves.

2. Care and support arranged and paid for by the local authority on the person's behalf.

3. The local authority can choose, organise and pay the service provider directly.

4. A combination of the above.

The equivalent in England and Wales is a personal budget.

\section{Housing for Disabled People}

The process of deinstitutionalisation characterised one of the most substantial changes in policy for disabled people (Bigby \& Fyffe, 2006; Ericsson \& Mansell, 1996; Kozma, Mansell, \& Beadle-Brown, 2009). This legislative change is now recognised as an international right under article 19 of the United Nations Convention on the Rights of Persons with Disabilities (United Nations, 2006). In England, the Care Act 2014 discourages residen- tial settings which are separated from general communities and emphasises person-centred approaches and the use of community-based options (Department of Health and Social Care UK, 2014). In Scotland, since the enforcement of the Social Work (Scotland) Act 1968, local councils have a duty to assess and ensure the person's community care needs and their preferences are taken into account when working with them (Social Security Directorate, 2019). This approach is carried through in the Adult Support and Protection Act 2007 and in the Social Care (Self-Directed Support) (Scotland) Act 2013.

After these changes took place, several reviews (Ericsson \& Mansell, 1996; Kozma et al., 2009; Mansell \& Beadle-Brown, 2009) reported that people with intellectual disabilities experience better outcomes in community-based and personalised housing solutions. These settings can vary significantly depending on where they are placed. Stereotypically, institutions would be large buildings, segregated from the local community, with a regulated and restrictive environment. Conversely, community-based and personalised housing puts the emphasis on a person-centred approach and enables the use of community-based services. There are usually ordinary or purpose-built group homes, that could either be dispersed or clustered, and potentially with supported living (Mansell \& Beadle-Brown, 2009). The outcomes in these housing solutions are, however, influenced by the support provided within these settings with Bigby, Knox, Beadle-Brown, Clement, and Mansell (2012) finding support staff engage in practices resembling those of institutions, such as centring work practices on staff rather than residents. This is, in part because a significant proportion of housing for disabled people, and indeed other marginalised and/or vulnerable groups such as homeless people, those with mental health needs or managing drug or alcohol addiction in the UK is provided by charitable organisations as part of their supported housing offer. As such, tenure of accommodation is linked to the exclusive provision of support (Mencap, 2018). This limits choice of provision for marginalised groups and means that the provision is frequently inflexible. In practice this results in residents being unable to leave their homes without support worker permission and service provider applied bed and meal-times to fit in with staff change-overs and medication, thus reproducing institutional practice under the guise of providing 'personcentred' support. This leaves residents unable to change support provision without changing accommodation provision, effectively rendering them captive. As such, supported accommodation in the UK is exempt from rules limiting the maximum housing benefit payable.

This form of housing also provides a significant level of income for providers and is under-regulated (Raisbeck, 2018). As per the United Nations Special Rapporteur for housing, housing for disabled people ought to be centred within communities, be accessible and fit for lifetime occupancy, and allow freedom of choice and flexibility about provision of support (Farha, 2017). The Equality 
and Human Rights Commission report into the housing experiences of disabled people in the UK found that housing for disabled people across the UK is mostly social housing provision and many disabled people have inaccessible homes. For example, in 2015, there were 40,000 Scottish households where individuals could not get in and out of their own home (Satsangi et al., 2018, p. 68).

In attempting to define different housing alternatives available to disabled and/or older people, the picture is complex with various terms describing seemingly similar forms of support. Scholars have attempted to define various housing approaches, and their impact on residents (Felce, Lowe, \& Jones, 2002; Finlay, Walton, \& Antaki, 2008). Another focus has been the size of setting and profile of the people supported (Mansell, Knapp, Beadle-Brown, \& Beecham, 2007). This terminology can be arranged in terms of location within the community and level of choice and control (Harflett, Pitts, Greig, \& Bown, 2017).

The key forms of housing are:

1. Mainstream: Housing not specifically designed for disabled/older people.

2. Designated: Housing specifically designed for and available to, disabled/older people.

Designated housing can be segregated or dispersed (Kozma et al., 2009; Mansell \& Beadle-Brown, 2009) with dispersed housing consisting of group homes in which small numbers of people live together in the wider community supported by staff (Mansell \& BeadleBrown, 2009).

Segregated housing can be categorised thus:

1. Campus settings, aimed at people with higher support needs, often located within the grounds of former institutions.

2. Cluster, or 'clustered housing,' aimed at disabled people living on the same site, in a relatively small number of houses within a mainstream community.

3. Intentional communities, for people with intellectual disability (characteristically mild) to share their space and daily life with support workers. Examples are Camphill and L'Arche communities.

Independent or supported living falls between mainstream and designated housing. This form of housing responds to the rights of disabled people to rent or own a home. The support can be offered as a domiciliary service, from a provider of their choice and as required (Harflett et al., 2017).

The level of choice and control disabled people have is closely linked to the form of housing tenure:

1. Full choice of care and support: Residents have complete control of their support, as it is sep- arate from housing provision and therefore not interdependent.

2. Some choice of care and support: Residents have some freedom in choosing care services. Some may be linked to housing provision.

3. Minimal choice of care and support: Residents have no control over care provision, as it is linked to accommodation.

\section{Background and Method}

\subsection{The Housing System Developed for This Intervention: SmartBodes}

The data for this article is taken from an evaluation of a new estate of technology-enhanced homes pseudonymised as SmartBodes. SmartBodes were developed in coproduction with manufacturers, housing society, healthcare providers and tenants. SmartBodes were designed to be highly functional, easily adaptable and suitable for a wide range of health and mobility needs and aimed to promote wellbeing and preventative health solutions including end of life care. The technology within the homes is a combination of passive sensors, such as movement sensors, 'internet of things'-enabled devices such as fridges, cookers, showers etc, and bed and chair sensors. The data generated is anonymously analysed by researchers at Robert Gordon University to help aid prediction of events which impact upon health, such as falls (Massie, Forbes, Craw, Fraser, \& Hamilton, 2018). It is important to note that, at the time of interviewing, this data was not actively used to support residents' health by health services. All residents were given a secure link to the live data stream for their home and could, if they so wished, share this with family, friends or carers. The live data stream was accessed by some families and at least one family reported that they had been alerted to a relative falling by the data feed.

Although SmartBodes were envisioned as 'lifetime' homes (Imrie, 2006), this first iteration was piloted with residents who were all identified by professionals as disabled and in need of various levels of support, either due to old age, physical illness and cognitive or physical impairment, with several residents living with multiple conditions. Thus, only disabled people were eligible to be allocated a SmartBode.

Residents in the SmartBodes access various forms of support. Unlike many forms of designated housing for disabled people, although one has to be disabled to be eligible for a SmartBode, tenancy is not tied to an individual support provider and the accommodation is not officially designated as supported accommodation. Indeed, one of the assumptions in the design of the SmartBodes, was that the need for support would be reduced given the improved accessibility afforded by lower surfaces, walk in/wheel in wet rooms and sliding doors. In total six residents interviewed had some form of professional support (either paid for from a care agency or free from 
a charity). This ranged from a cleaner coming in a couple of times per week, paid for privately, to 1:1 support 24 hours per day. Eight residents, including three who had access to formal support, also had informal, family support. Only one resident reported having neither formal nor informal support. Of those five residents who only had access to informal support, only one said it was insufficient. One resident who received formal support, felt the support received was insufficient to live independently and had to rely on family to fill the gaps. Another resident, who previously had dwindling levels of support and who lost all support following the move, reported the informal support was sufficient most of the time.

The research team conducting the evaluation of this intervention developed a bespoke methodology, drawing on the principles of Realist Evaluation (Pawson \& Tilley, 2004), Theory of Change (Harries, Hodgson, \& Noble, 2014) and Social Return on Investment (SROI; Nicholls, Lawlor, Neitzert, \& Goodspeed, 2009) to produce overall evaluation findings, which were presented to the Housing Association that developed the SmartBodes. Interviews with SmartBode tenants were nested within this overall evaluation methodology-and the research presented in this article draws only from the qualitative interviews with tenants. As our wider evaluation was grounded in the principles of Realist Evaluation, it was mixed methods-collecting questionnaire, interview and other contextual data. In being cognisant of context, our underpinning methodological framework allowed us to collect information on the key questions of Realist Evaluation-what works, for whom, in what circumstances and why-and in doing so, we simultaneously collected the data required for an SROI calculation that was disaggregated by different types of tenant. Realist Evaluation is theory driven and was appropriate for our evaluation which firstly mapped a theory of change (or programme theory) for the SmartBode development-this mapped the intended and anticipated outcomes of the development from the point of view of the different stakeholders.

We were able to use this theory of change to inform the questions that were included in our tenant questionnaires and interviews, as well as the different types of wider, contextual data that we collected and to compare the actual outcomes with those that were anticipated by stakeholders at the start of the project. Thus, the key characteristics of our overall methodology for the evaluation research resulted from our combination of Realist Evaluation and SROI-it was mixed methods, involved the identification of key stakeholders as well as their roles and experiences of involvement in the SmartBode development and was cognisant of context and how experiences differed between individuals. However, this article considers the experience of tenants in-depth by drawing on our qualitative data and our interview methods are outlined in detail below.

Ethical approval was obtained from the University of the Highlands and Islands. A user-friendly participant in- formation sheet described the evaluation and was provided to the participants by the housing provider who then obtained consent from the residents for the researchers to contact them. Those who agreed ( $n=13$ ) were then contacted by telephone to arrange interview times at which point the researcher went through the information sheet again, together with the consent form. The consent was signed before the interview commenced. It was made clear that participants could refuse to answer any questions without giving a reason, and that they could terminate their participation at any time. It was emphasised that refusal to participate would not impact on their offer of a SmartBode.

Interviews were audio recorded with prospective residents $(n=13)$ in their previous home or in a relative's home before moving into their allocated SmartBode. Residents were then re-interviewed $6 / 7$ months after moving ( $n=12$ ). Interviews consisted of a short questionnaire delivered orally, followed by a semi-structured interview which probed questionnaire responses. Not all respondents from the first stage of interviewing relocated and three respondents in the second stage were unavailable to interview for the first stage. Thus, in the second interview phase, nine residents were interviewed for the second time and three for the first time. In the second round, from which the analysis is taken, three participants were interviewed with carers or family present at their request. Recordings were transcribed verbatim and then analysed using thematic analysis. Because of the unique nature of the project, small sample size, diversity of residents and sensitive nature of some of the data, we have not used any identifiers to connect quotations and have removed impairments, ages and genders to protect the anonymity of respondents.

\section{Analysis}

\subsection{Loneliness}

Tenants were asked to quantitatively rate their levels of loneliness before and after relocating and were also asked about loneliness and their social interactions during the semi-structured part of the interviews. It is notable that whilst some tenants did not report high levels of loneliness in the questionnaires prior to relocation and afterwards, examples of social isolation were significant during the interviews. For example, one resident said the only person they used to see in the week was the milkman. For some residents, isolation was a consequence of ageing or impairment and was therefore normal:

Loneliness, I wouldn't say it's a factor, no. I'm not lonely. Well I suppose you do get lonely sometimes...but I'm used to it.

One respondent, a wheelchair user in an inaccessible property, found the social isolation before moving was extreme despite reporting in the questionnaire that they 
seldom felt lonely:

I haven't been in a shop since years. I'm not talking about weeks but years....The nurse was quite right when she said, "you're a prisoner in here." I cannot go out the back [door] and I can't go out the front [door].

In this case, the long-term social isolation from before moving continued well after relocating, so, although the new home was wheelchair accessible, the psychoemotional impact (Reeve, 2004) of previously being housebound, was profound:

I just canna bring myself just to go out....It left a mark on me, yes. That hurts, up there [points to head]. I think I've said-well, I was a prisoner in there.

This did not, however, reduce their desire for human company:

That [resident] next door... [they] came in here after me, and I said all along I need to go and speak to [them]. I haven't done it.

But despite this, going outside felt like an insurmountable task:

I was going to go across and see [resident $B$ ] that came out [resident B was observed through the window during the interview] but I could find different reasons for not going, which was a lot of rubbish actually.

In total four residents interviewed continued to experience loneliness and isolation. The reasons were complex, but key factors were reduced mobility, lack of local connections, psychological barriers and, in one case, overt exclusion by others in the community. Some isolated residents found even seeing others in passing or through the window an improvement on their previous situation:

Well the only one I really see is [resident], [they] live in the house just there....It's just nice just to go out sometimes and you see somebody. Whereas before, where I was, apart from carers coming in, I never really saw anybody....I mean I couldn't just sit like just now and look out glass and see people passing.

Some residents made concerted attempts to include others. These overtures were received very differently, depending on the individual. This resident, who was well known to other residents and their families before relocating, made selective contact with other residents:

I was never really one for going in and out of people's houses or vice versa, I pick, I choose...

They reached out to a fellow resident they had known for a long time previously:
I went over one day and I went, "Hey you, what are you still doing in here?" [Y] knows me. [Y says] "I can't explain it, I don't want to go out." I says, "Look, don't let anybody force you, I'm just saying if you feel like coming out, everybody is out and about." I go over now and again and see $[Y]$.

They also had regular contact with their neighbour, one of the more isolated residents, visiting them most days. Both residents regarded these interactions positively:

I went over to see [resident] yesterday and I took the [grandchildren]....They gave [resident] a wee hug when we were coming away and [resident] says, "Och, I've never did that in a long time," and I think [they were] happy that the bairns had...[provided human contact]

Attempts at contact by two isolated residents were unsuccessful, however, and involved 'policing' by both neighbours and housing officials - in one instance for not making attempts to engage, and in another, for attempting to engage too much:

Somebody said that I haven't spoken to anybody here, well the day I came, I walked down to the bottom and spoke to every one of them in the houses as I walked down, and said hello and who I was. And not one soul came up or anything, they've never been here either.

In this instance the resident eventually developed a good connection with their neighbour although they did not report any interactions with other neighbours. The following quotes from another resident (resident $\mathrm{X}$ ) who made attempts to get to know the other residents, had a significantly more negative outcome:

I get into bother because I knocked on half a dozen doors and introduced myself. "Just keep yourself to yourself," you can't believe that, can you?

Resident $\mathrm{X}$ acknowledged they may have been somewhat culpable in trying to interact with a resident inappropriately:

[They've] backed off from me, I went to the door probably more than I should have and [they] didn't answer.

The policing, which arose following a complaint by another resident, had a significant impact on the isolation and emotional distress felt by resident $\mathrm{X}$ :

It's so petty. I got quite upset, especially when they'd said, "Just keep yourself to yourself." And I got so upset and I thought "How dare you try to control my life and tell me what to do and what not to do?" So much for community spirit. 
This isolation and exclusion from the community felt by resident $X$ was underlined by other residents, some of whom, such as this respondent, spoke disparagingly about them:

Basically, most of the neighbours are really nice, there's one neighbour that I don't like and nobody really around here likes [them].

Such instances of social isolation were only relieved by family or formal carers. Despite this, only resident $\mathrm{X}$, discussed above, explicitly reported higher levels of loneliness and isolation, qualitatively and quantitatively, compared to before relocating:

I probably would have been quite isolated up at [area] as well...if it wasn't for this group of carers, I don't know what I'd do. They are all different individual personalities...and I need that because I'm a people person.

Most residents interviewed, however, reported decreased loneliness and feelings of social isolation since moving, as the following quotation indicates.

No, I don't feel lonely and there's always someone about here that I can see...just lots of people walking about.

\subsection{Building Community}

A possible reason loneliness generally decreased since relocating was because it appeared that residents had rapidly established a nascent community.

Other people get on with other people so it's a real community, you can see that. And you can see it more in the summer because everybody was about.

This can partly be attributed to most residents moving in simultaneously, although this did not mean that residents who moved later necessarily found it difficult to connect with neighbours:

Most of the other neighbours had moved in [ $x$ weeks] before, so they all knew everybody but there was the [resident] who is living in number [x], I knew [them] from when I was up at the old place because [they] was one of my...neighbours.

Another factor in helping to establish the community is indicated towards the end of the quote above. Most people who moved into the estate also came from the same area and many knew each other beforehand. In some instances, these networks were quite extensive, the stable communities supporting the development of far-reaching kith (Ellis, 2017) networks:
I know a lot of people...that's moved from my end down to [here] - [resident A] I'm quite pally wi,' I was pally with [their] brother...[resident B]...I'm pally with [their] sons....About $98 \%$ of them know me and my family, we're quite well known.... know [resident C], [their] father stays straight across from my mum's, that's where [they] used to live until [they] got [their] own accommodation down here. I know [resident B], I know [resident A], I know [their] parents too and [their] dad quite well....[Resident D] that's up there, I know [them] too.

These prior connections helped support neighbourliness and most residents reported getting along well with their neighbours. Neighbour interactions varied in their level of interpersonal intensity. Community organising engaged all residents and there was a communal concern for each other's wellbeing. For example, the communal outside lighting was considered inadequate. One resident expressed concern, although not personally affected, because they believed it constituted a fall risk for other residents. However, the use of the outside lighting attached to the homes was also considered to be anti-social, so there was a consensus on not using them:

We don't want to put these big lights on because they shine right across into somebody else's window and you don't want to do that.

Residents communicating with each other on a regular basis acted to alert others of potential issues. This use of chat as a form of social glue (Ellis, 2017; Falk \& Kilpatrick, 2000) strengthened the community itself, with residents being alert to outside threats such as strangers peering into windows.

Whilst residents were keeping an eye open generally, there was an awareness of being respectful of personal space:

I know one or two of the people that have moved in. But I don't go knocking on people's doors and inviting myself in, I just don't do that.

\subsection{Building Support}

The prior social links and informal communications within the estate, resulted in residents feeling supported and more confident:

I wasn't going to go in [to hospital] but now there's somebody here to look after the animals I will go and get things done. That gives me more confidence.

This often resulted in direct instances of neighbours providing practical, informal support particularly for those who had physical or mobility impairments: 
And I'll take parcels in the post for [them] if [they] needs that...and I can see the lights are on so it's fine....We all help each other out and if I wasn't feeling safe, I could phone some of them [neighbours].

This watchfulness increased feelings of independence and confidence for some residents, particularly those who were not receiving formal forms of support. This informal support varied from providing support in a psychological crisis to more personal support:

I was quite upset one day, I was roaring and greeting like a banshee and the windows must have been open because the lot down there, [resident's] relatives heard me and they came in.

I dress myself and all that and obviously I put my arm in first, but twice I got tangled up in my shirt....So it was [resident $B$ and resident $A$ ] that helped me out.

Some housebound residents also report feeling connected to their neighbours and able to show concern for them in addition to purely social interactions:

If [they] can see me through the window, [they'll] go like this [waves], and I'll know [they're] alright! No, it's nice having someone that close that you can talk to, and then [they] pops in.

\subsection{Socialising}

Many residents interviewed reported engaging in significant levels of social interaction, which can partly be attributed to self-organising by residents. The interview data demonstrated that much of the community organisation, from petitions to arranging games nights was carried out by one very active resident within the estate:

We're quite good at doing that [self-organising]....If we say we're going to have something we always say "anybody want to come down, just come down" and we have a good laugh.

Socialising between residents was also supported by good weather that first summer on the estate, with many residents using the outside spaces and congregating together:

Everybody seems to come down here and sit and have coffee and tea or whatever, so it's been really good, this summer has been fantastic and I absolutely love that decking out there.

Some residents expanded the socialising during daytime into the evenings with residents reporting having games nights and even going to play bingo in the local town:

It's good that we all...meet up and talk and have a coffee or a blether or have a wee night [out].
The active community has resulted in people creating new friendships:

I have got a friend now, the lady next door, we chat every day and she comes in....[Resident] is a good woman she is, she is nice. She always comes in, every day.

\subsection{Pets as Social Glue}

Pets were an important element within the estate, providing company for owners and, in the case of dogs, encouraging residents to exercise and leave the house:

Well I take the dog for a walk every day, maybe two or three times a day...

Pets also worked as a form of social glue, with residents either visiting their pet-owning neighbours or helping with dog walking:

Neighbours, I see them all the time. I see [resident] every day....Because I take [their] dog [for] a walk every day, depends on the weather. If it's wet I don't.... still go over, but not to take the dog [for] a walk.

The social value of pets is thus recognised by non-pet owners with some neighbours expressing a desire to own a pet. In this quote, the response by the support worker highlights the further potential of pets to provide social interaction:

Respondent: I feel like if I had a dog, it would give me an incentive to go out because I have to take the doggie out. You just felt "I've got to." But och, they are good company when you are by yourself.

Support worker: What we should do is speak to your neighbours who have got dogs and get them to come by and see if you want to go out for a walk with them when they take the dog out and start there.

\section{Discussion}

\subsection{A Hybrid Housing Type}

We have presented the thematic analysis of qualitative data collected through interviews with tenants of one smart home social housing development in Scotland. This housing development has characteristics of several of the existing categorisations of housing present in the academic literature (Harflett et al., 2017; Kozma et al., 2009; Mansell \& Beadle-Brown, 2009). Thus, it can be considered a hybrid housing type; simultaneously designated, segregated, clustered and a form of independent living in which residents have a high level of control over support provision. Its physical design, and the design of the associated tenancy allocations process, mean that it 
is 'designated' as only available to disabled people, usually identified as potential tenants by a health/social care professional; 'segregated' from other homes within the social housing estate as the SmartBode homes are located next to each other and stand out in terms of their innovative and unusual design; 'clustered' as people live on the same site in a small group of homes; and 'independent living' as all SmartBode homes are rented by the disabled people. However, they are first and foremost designated as technology supported life-time homes (Imrie, 2006). They are segregated, but their occupiers are diverse in terms of age, impairments and support needs. They are clustered, but a cluster of Smart Homes. It is hard to put a label on them and this, in itself, perhaps prevents negative (self) labelling by their occupiers.

\subsection{Loneliness and Social Isolation/Connection}

Our interviewees indicated that levels of loneliness generally decreased following their move to a SmartBode. This was sometimes not explicitly noted in their quantitative responses, but in their qualitative data it was apparent that their amount of social interaction had increased following the move-they saw and talked to more people. This was often partly due to the physical structure of the SmartBode, meaning they could move around and in/out of their homes more easily. We have seen that many of the SmartBode tenants made relatively short distance moves into their new homes and, thus, were able to maintain existing social connections within the local community-this connection has been shown to be generally positive for mental wellbeing (Wilkinson \& Ortega-Alcázar, 2019). However, we also saw that, after moving to the SmartBodes, some residents continued to experience social isolation and loneliness, demonstrating its complex nature (ONS, 2018).

\subsection{A Community That Supports Itself}

Our analysis has shown that a move into clustered-style housing is not necessarily associated with feelings of selfstigma or ghettoisation. It appears the SmartBodes manage to be both clustered and individualised enough to meet people's needs and maintain their sense of self, so that negative connotations are not evoked. We have seen that a sense of community amongst the SmartBode tenants had rapidly developed (Dinnie \& Fischer, 2020). For most people, this was a positive experience although our analysis shows that a good proportion of the more formal 'social organising' was done by one tenant, without whom things may have progressed differently. In addition, the fact that most tenants relocated at the same time, helped to foster a shared sense of community. Those who relocated later, tended to be less well connected to their neighbours. Our analysis also suggested the rapid formation of a sense of community was at least partly dependent on the fact that some tenants had existing connections to each other prior to relocating. The level of support experienced by participants, be they formal or informal, appeared to have little to do with feelings of connection with each other or the wider community, although it is arguable that for some residents who had no formal support, this factor prompted informal support from neighbours. However, socialising with neighbours was not contingent upon having support from family or carers. The resident who had 24-hour formal support was as active in the community of SmartBodes as some residents who had no support at all.

It would be disingenuous to say that all residents felt included in the nascent community, but generally there was a feeling of mutual concern for each other's wellbeing. Our interviews revealed that tenants were cognisant of the fact that they were part of a housing cluster for people with additional support needs and, therefore, often took it upon themselves to 'care' for their neighbours in different ways. The clustered aspect of the SmartBode development seemed, therefore, important in building peer-to-peer support. It is positive that, as a community, everyone looks out for each other, but this informal community support is no substitute for statutory care because people who are excluded can miss out (Overmars-Marx et al., 2014).

\section{Conclusion}

Within the context of a wider shift from segregated housing, towards supported housing within the wider community, this article has considered the experience of a particular cohort of social housing tenants who recently moved into a hybrid type of clustered housing. We have shown that this cohort of people had varying characteristics, but all were living with some form of disability, agerelated impairment or long-term condition. Our cohort moved into a cluster of purpose-built homes within a new built social housing estate. These homes were designed to be 'lifetime homes,' able to adapt with the shifting needs of the cohort. They incorporated elements of smart home technology. In many ways, they therefore meet requirements set out by the UN for disabled people's housing to fulfil their rights to adequate, accessible housing and the right to community life (Farha, 2017). A new term is needed to describe this emergent housing type of accessible, lifetime estate homes aimed at people with diverse levels of support need-perhaps Clustered SmartHomes?

Through the analysis of qualitative data, collected through interviews with tenants, this article has identified the social and emotional impacts of the move from the perspective of the tenants themselves. In particular, we have explored what impacts on their individual wellbeing, sense of social connection and community. The hybrid nature of the SmartBode housing development may be one of the things underlying the generation of social connectedness and community that has not been observed in some other clustered housing developments, 
as they provide independent living; a sense of security, watchfulness and social interaction for those who want it; and independent privacy for those who do not.

However, communities are simultaneously inclusive and exclusive. It would be easy to romanticise the way that this community has rapidly developed and drawn together-the significant reductions in loneliness and wellbeing improvements make it seductive, but to do so would be to turn a blind eye to the loneliness that some residents continue to experience, not to mention the deliberate ostracising of one resident.

Nevertheless, the SmartBode development allowed many of the residents to make relatively short distance moves into the homes, allowing them to maintain existing social networks. Generally, this helps people maintain informal and communal forms of support by kith (Ellis, 2017) and family. Our analysis also suggests that the clustered element of the SmartBode development contributed to positive feelings of watchfulness and security for some tenants, that sat alongside the facilitation of peer-to-peer support through residential proximity. In a way, the SmartBodes show us what all communities could be: the integration of life-long homes with technological support to enable people to age in place; to foster and maintain the social networks and linkages they want and need within the communities in which they have already built them. Having developments like SmartBode available locally, even on a small scale such as the 16-home development considered in our research, would go some way towards helping people age in place whilst reaping the benefits of maintaining established social networks. Future housing policy may wish to consider an obligation on new build developers to include not only affordable, life-time housing but an area of clustered SmartHomes.

\section{Acknowledgments}

The evaluation was funded by Scotland's Digital Health and Care Institute (DHI). The authors would like to thank all participants.

\section{Conflict of Interests}

The authors declare no conflict of interests.

\section{References}

Bigby, C. (2004). But why are these questions being asked? A commentary on Emerson (2004). Journal of Intellectual \& Developmental Disability, 29(3), 202-205.

Bigby, C., \& Fyffe, C. (2006). Tensions between institutional closure and deinstitutionalisation: What can be learned from Victoria's institutional redevelopment? Disability and Society, 21(6), 567-581.

Bigby, C., Knox, M., Beadle-Brown, J., Clement, T., \& Mansell, J. (2012). Uncovering dimensions of culture in underperforming group homes for people with severe intellectual disability. Intellectual and Developmental Disabilities, 50(6), 452-467.

Cummins, R. A., \& Lau, A. L. D. (2004). Cluster housing and the freedom of choice: A response to Emerson (2004). Journal of Intellectual and Developmental Disability, 29(3), 198-201.

Department of Health and Social Care UK. (2014). Care and support statutory guidance. Government UK. Retrieved from https://www.gov.uk/government/ publications/care-act-statutory-guidance/care-andsupport-statutory-guidance

Dinnie, E., \& Fischer, A. (2020). The trouble with community: How 'sense of community' influences participation in formal, community-led organisations and rural governance. Sociologia Ruralis, 60(1), 243-259.

Ellis, L. (2017). Reclaiming kith: Weaving belongingness into community. In K. Soldatic \& K. Johnson (Eds.), Disability and rurality: Identity, gender and belonging (pp. 215-232). London: Routledge.

Emerson, E. (2004a). Cluster housing and freedom of choice: A response to Cummins and Lau's and Bigby's commentaries. Journal of Intellectual and Developmental Disability, 29(3), 187-197.

Emerson, E. (2004b). Cluster housing for adults with intellectual disabilities. Journal of Intellectual and Developmental Disability, 29(3), 187-197.

Ericsson, K., \& Mansell, J. (1996). Deinstitutionalization and community living. Boston, MA: Springer US.

Falk, I., \& Kilpatrick, S. (2000). What is social capital? A study of interaction in a rural community. Sociologia Ruralis, 40(1), 87-110.

Farha, L. (2017). Report of the special rapporteur on adequate housing as a component of the right to an adequate standard of living, and on the right to nondiscrimination in this context: Vol. A/72/128. New York, NY: United Nations General Assembly.

Felce, D., Lowe, K., \& Jones, E. (2002). Staff activity in supported housing services. Journal of Applied Research in Intellectual Disabilities, 15(4), 388-403.

Finlay, W. M. L., Walton, C., \& Antaki, C. (2008). Promoting choice and control in residential services for people with learning disabilities. Disability and Society, 23(4), 349-360.

Harflett, N., Pitts, J., Greig, R., \& Bown, H. (2017). A proposed typology of housing and support (Housing Choices Discussion Paper 2). Bath, Lancashire and Glasgow: National Development Team for Inclusion. Retrieved from https://www.ndti.org.uk/resources/ publications/housing-choices-discussion-paper-2

Harries, E., Hodgson, L., \& Noble, J. (2014). Creating your theory of change: NPC's practical guide. London: New Philanthropy Capital. Retrieved from https://www.thinknpc.org/wp-content/uploads/ 2018/07/Creating-your-theory-of-change1.pdf

Imrie, R. (2006). Independent lives and the relevance of lifetime homes. Disability \& Society, 21(4), 359-374.

Kozma, A., Mansell, J., \& Beadle-Brown, J. (2009). Out- 
comes in different residential settings for people with intellectual disability: A systematic review. American Journal on Intellectual and Developmental Disabilities, 114(3), 193-222.

Mansell, J., \& Beadle-Brown, J. (2009). Dispersed or clustered housing for adults with intellectual disability: A systematic review. Journal of Intellectual \& Developmental Disability, 34(4), 313-323.

Mansell, J., Knapp, M., Beadle-Brown, J., \& Beecham, J. (2007). Deinstitutionalisation and community livingoutcomes and costs: Report of a European study (Vol. 2). Boston, MA: Springer US.

Massie, S., Forbes, G., Craw, S., Fraser, L., \& Hamilton, G. (2018). Fitsense: Employing multi-modal sensors in smart homes to predict falls. In M. Cox, P. Funk, $\mathrm{S}$. Begum (Eds.), Case-based reasoning research and development. ICCBR 2018. Lecture notes in computer science (Vol. 11156; 249-263). Stockholm: Springer.

McConkey, R., Keogh, F., Bunting, B., Iriarte, E. G., \& Watson, S. F. (2016). Relocating people with intellectual disability to new accommodation and support settings: Contrasts between personalized arrangements and group home placements. Journal of Intellectual Disabilities, 20(2), 109-120.

Mencap. (2018). Funding supported housing for all. Specialised supported housing for people with a learning disability. London: Mencap. Retrieved from https://www.mencap.org.uk/sites/default/files/ 2018-04/2018.052Housingreport_FINAL_WEB.pdf

Merrells, J., Buchanan, A., \& Waters, R. (2019). "We feel left out": Experiences of social inclusion from the perspective of young adults with intellectual disability. Journal of Intellectual \& Developmental Disability, 44(1), 13-22.

Ministry of Housing Communities \& Local Government. (2019). Housing for older and disabled people. Government UK. Retrieved from https://www.gov.uk/ guidance/housing-for-older-and-disabled-people

NHS. (2018). Financial assessment (means test) for social care. NHS. Retrieved from https://www.nhs. uk/conditions/social-care-and-support-guide/helpfrom-social-services-and-charities/financialassessment-means-test

Nicholls, J., Lawlor, E., Neitzert, E., \& Goodspeed, T. (2009). A guide to social return on investment. Lon- don: Office of the Third Sector, Cabinet Office.

ONS. (2018). Understanding the sources of loneliness. British Journal of Healthcare Assistants, 12(6), 303-307.

Overmars-Marx, T., Thomése, F., Verdonschot, M., \& Meininger, H. (2014). Advancing social inclusion in the neighbourhood for people with an intellectual disability: An exploration of the literature. Disability and Society, 29(2), 255-274.

Pawson, R., \& Tilley, N. (2004). Realist evaluation. Newcastle upon Tyne: Sage.

Power, A., \& Gaete-Reyes, M. (2019). Neoliberal abandonment in disability housing provision: A look at England and Chile. Housing Studies, 34(5), 741-760.

Raisbeck, T. (2018). Risk, safety and wellbeing in shared 'exempt' accommodation in Birmingham, England. Birmingham: Spring Housing Association. Retrieved from https://www.housinglin.org.uk/_assets/ Resources/Housing/OtherOrganisation/Risk-Safetyand-Wellbeing-in-Shared-Exempt-Accommodationin-Birmingham-Full-Report.pdf

Reeve, D. (2004). Psycho-emotional dimensions of disability and the social model. In C. Barnes \& G. Mercer (Eds.), Implementing the social model of disability: Theory and research (pp. 83-100). Leeds: The Disability Press.

Satsangi, M., Theakstone, D., Matthews, P., Lawrence, J., Rummery, K., Mackintosh, S., Boniface, G. (2018). The housing experiences of disabled people in Britain. Equality and Human Rights Commission. https:// www.equalityhumanrights.com/en/publicationdownload/housing-experiences-disabled-peoplebritain

Social Security Directorate. (2019). Social security: A consultation on disability assistance in Scotland. Government Scotland. Retrieved from https://www. gov.scot/publications/social-security-consultationdisability-assistance-scotland

United Nations. (2006). Convention on the rights of persons with disabilities. New York, NY: United Nations.

Wilkinson, E., \& Ortega-Alcázar, I. (2019). Stranger danger? The intersectional impacts of shared housing on young people's health \& wellbeing. Health and Place, 60. https://doi.org/10.1016/j.healthplace. 2019.102191

\section{About the Authors}

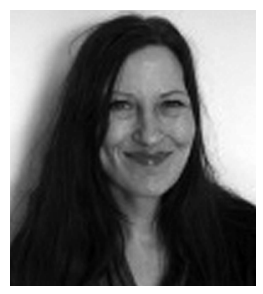

Liz Ellis is a Post-Doctoral Researcher with a background in Critical Disability Studies and inclusive research. Her current research is around the use of co-production to achieve stakeholder-led outcomes. She mostly works using qualitative and emancipatory approaches and has a specific interest in learning disabilities, social inclusion and rural sociology. 


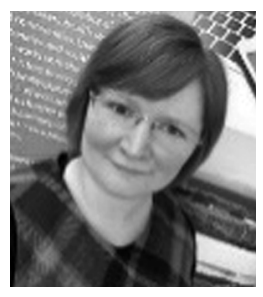

Sarah-Anne Muñoz is a Health Geographer and Acting Head of the Division of Rural Health and Wellbeing at the University of the Highlands and Islands. She is broadly interested in the relationships between health and place and has expertise in qualitative and participatory research, as well as health services evaluation.

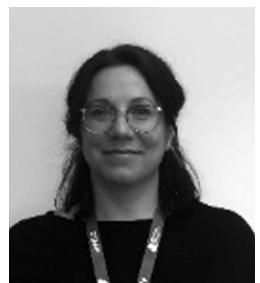

Katia Narzisi holds a PhD in Health and Social Care and has worked in academia since 2016. Her research is focused on health inequalities and human rights. She works with marginal populations, hard to reach participants and rural communities. Her research interests extend across sociological, legal, cultural, behavioural factors affecting health and wellbeing in young people and marginal populations.

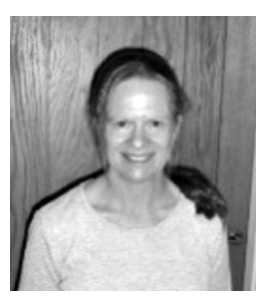

Sara Bradley is a Research Fellow with extensive experience of carrying out qualitative and evaluative work in rural health contexts. Her research interests include social gerontology, social prescribing and the use of green exercise and non-pharmaceutical interventions to promote health and mental wellbeing.

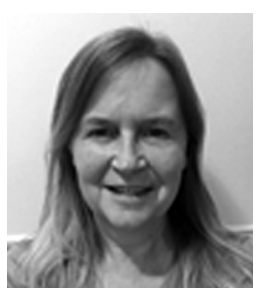

Jenny Hall is a Post-Doctoral Researcher with a background in quantitative research. Current research interests include social return on investment analysis and improving access to health services for people in remote and rural areas. 